\title{
Evolución del programa de trasplante renal en la provincia de Cádiz
}

\author{
Andrés Moreno Rodríguez, Lourdes Benitez Ruiz, Rosa Sanz García
}

Hospital Universitario Puerta del Mar. Cádiz

\section{Objetivos:}

Analizar las características y la evolución del programa de trasplante renal

\section{Métodos:}

Diseño: estudio retrospectivo y descriptivo. Periodo de estudio: 1982-2012 divididos en 3 periodos, $1^{\circ}$ (19821992), $2^{\circ}$ (1993-2002) y $3^{\circ}$ (2003-2012). Ámbito: Hospital Universitario de referencia para el trasplante renal que abarca una población de 1.243 .519 habitantes. Variables: Actividad extractora trasplantadora.

\section{Resultados:}

835 donantes de órganos y/o tejidos de cadáver, 8 de ellos fueron donantes de órganos en asistolia. 1163 trasplantes renales de ellos 700 implantes renales funcionantes (60\%). 62 donaciones renales de vivo a vivo, 4 trasplantes renales procedentes de donación de vivo cruzada. 43 riñones fueron extraídos con técnica de laparoscopia y 20 por laparotomía. 6 pacientes trasplantados eran portadores del VIH.

\begin{tabular}{c|c|c|c|c|c|}
\multirow{2}{*}{ AÑOS } & $\begin{array}{c}\text { M. ENCEF./ } \\
\text { DONANTES }\end{array}$ & \multicolumn{2}{|c|}{ TX RENAL } & \multicolumn{2}{c|}{ TX R. VIVO } \\
\cline { 2 - 6 } & $\mathrm{N}^{\mathrm{a}}$ & $\mathrm{N}^{\mathrm{a}}$ & $\%$ Total & $\begin{array}{c}\mathrm{N}^{0}(\% \\
\text { periodo) }\end{array}$ & $\%$ Total \\
\hline $\begin{array}{c}1982- \\
1992\end{array}$ & NO DATOS & 156 & 13,6 & $7(4,5 \%)$ & 11,3 \\
\hline
\end{tabular}

\begin{tabular}{|r|r|r|r|r|r|}
\hline $\begin{array}{c}1993- \\
2002\end{array}$ & $675 / 260$ & 454 & 39,5 & $9(2 \%)$ & 14,5 \\
\hline $\begin{array}{c}2003- \\
2012\end{array}$ & $617 / 302$ & 539 & 46,9 & $46(8,5 \%)$ & 74,2 \\
\hline TOTAL & $1292 / 562$ & 1149 & & $62(5,4 \%)$ & \\
\hline
\end{tabular}

\section{Conclusiones:}

En nuestro centro el $n^{0}$ de trasplantes renales continúa en ascenso a pesar de la disminución de los donantes en muerte encefálica. Este hecho ha sido posible gracias al incremento de la donación de vivo a vivo producido en los últimos años, entre otros factores por la implantación de la técnica laparoscópica en este tipo de intervención y a la adecuada valoración de los donantes. Destacable el $n^{\circ}$ de trasplantes funcionantes y el buen resultado de los pacientes trasplantados portadores de VIH.

\section{Referencias Bibliográficas}

1. TRASPLANTE RENAL. Manual sobre donación y trasplantes de órganos. Editorial Aran. Pascual Parrilla, Pablo Ramírez; Antonio Ríos I Curso de donación y trasplantes para estudiantes de medicina de la universidad de Cádiz. Editores José Manuel Jiménez Moragas, Pilar Martínez García, Lourdes Benítez Ruiz, Francisco Carrizosa Carmona. Año 2011. 